\title{
Review Article \\ The Status of the Quality Control in Acupuncture-Neuroimaging Studies
}

\author{
Ke Qiu, ${ }^{1,2}$ Miaomiao Jing, ${ }^{1}$ Ruirui Sun, ${ }^{1}$ Jie Yang, ${ }^{1}$ Xiaoyan Liu, ${ }^{1}$ Zhaoxuan He, ${ }^{1}$ \\ Shuai Yin, ${ }^{1}$ Ying Lan, ${ }^{1}$ Shirui Cheng, ${ }^{3}$ Feifei Gao, ${ }^{1}$ Fanrong Liang, ${ }^{1}$ and Fang Zeng ${ }^{1}$ \\ ${ }^{1}$ The Acupuncture and Tuina School, The 3rd Teaching Hospital, Chengdu University of Traditional Chinese Medicine, \\ No. 37, Shierqiao Road, Chengdu, Sichuan 610075, China \\ ${ }^{2}$ Leshan Vocational \& Technical College, Leshan, Sichuan 614000, China \\ ${ }^{3}$ Dayi Chinese Medicine Hospital, Chengdu, Sichuan 611330, China
}

Correspondence should be addressed to Fanrong Liang; acuresearch@126.com and Fang Zeng; zeng_fang@126.com

Received 19 November 2015; Revised 3 March 2016; Accepted 27 March 2016

Academic Editor: Jeng-Ren Duann

Copyright (C) 2016 Ke Qiu et al. This is an open access article distributed under the Creative Commons Attribution License, which permits unrestricted use, distribution, and reproduction in any medium, provided the original work is properly cited.

\begin{abstract}
Using neuroimaging techniques to explore the central mechanism of acupuncture gains increasing attention, but the quality control of acupuncture-neuroimaging study remains to be improved. We searched the PubMed Database during 1995 to 2014. The original English articles with neuroimaging scan performed on human beings were included. The data involved quality control including the author, sample size, characteristics of the participant, neuroimaging technology, and acupuncture intervention were extracted and analyzed. The rigorous inclusion and exclusion criteria are important guaranty for the participants' homogeneity. The standard operation process of acupuncture and the stricter requirement for acupuncturist play significant role in quality control. More attention should be paid to the quality control in future studies to improve the reproducibility and reliability of the acupunctureneuroimaging studies.
\end{abstract}

\section{Introduction}

Acupuncture, a traditional therapy originated from China, has been gradually accepted as an alternative and complementary therapy by the Western medical community for its undeniable efficacy for pain and chronic diseases [15]. As acupuncture is widely used all over the world, its underlying mechanism attracts increasing attention. Since the 1970s, several studies of acupuncture on experimental animals have proven that the integration of central nervous system (CNS) plays an important role in acupuncture efficacy $[6,7]$. With the development of neuroimaging techniques such as functional Magnetic Resonance Imaging (fMRI), Positron Emission Tomography (PET), Single-Photon Emission Computed Tomography (SPECT), electroencephalography (EEG), and magnetoencephalography (MEG), using these techniques to investigate the cerebral responses to acupuncture stimulations in vivo [8] has gradually become a spotlight in acupuncture mechanism research. Over the past two decades, there are around 200 original articles having been published in English, and a growing body of evidence demonstrates the involvement of CNS in acupuncture mechanism [9]. However, it was found that the results of acupuncture-neuroimaging studies were untenable. For example, some studies on acupoint specificity showed that the cerebral responses to acupoint stimulation significantly differed from acupoint to sham acupoint [1013]. Some studies demonstrated that there was no significant difference in cerebral reaction between acupoint and sham acupoint [14-16]. Some investigators held that the significant difference in cerebral responses between acupoint and sham acupoint was only found during Deqi (needle sensation) state [17]. Methodology issues might contribute to the conflict results.

As we know, design and quality control are key points which may affect the result of a study, and strict quality 
control plays an essential role in the guarantee of a high repeatability, especially in acupuncture-neuroimaging study for relative smaller sample size, complexity of cerebral function, and integrity of acupuncture effect. So this study aims to investigate the current status of the quality control in acupuncture-neuroimaging studies from sample size, subjects screening, manipulation procedure, and scanning mode by analyzing the original articles published in English in the latest two decades, so as to provide ideas for the development of quality control criteria in future acupunctureneuroimaging study.

\section{Methods}

2.1. Searching Strategy. We searched the original articles published during 1995 to 2014 on PubMed (http://www.ncbi .nlm.nih.gov/pubmed/) using the following MeSH terms and search strategies: (("Acupuncture" [Mesh] OR "Acupuncture Therapy" [Mesh] OR "Acupuncture, Ear" [Mesh] OR "Acupuncture Points" [Mesh] OR "Acupuncture Analgesia" [Mesh])) AND (("Neuroimaging" [Mesh] OR "Functional Neuroimaging" [Mesh] OR "Functional MRI" [Mesh] OR "PET" [Mesh] OR “EEG” [Mesh])).

We screened the bibliographies of identified trials and reviewed articles for further potentially relevant publication. Subsequently, we screened the full texts and assessed whether these articles met the inclusion criteria.

2.2. Inclusion and Exclusion Criteria. The articles would be included if they were (1) original articles; (2) acupunctureneuroimaging studies on human beings; (3) published in English; and (4) published during 1995 to 2014.

The articles would be excluded if they were (1) reviews or editorials or trial protocols; (2) acupuncture-neuroimaging studies on animals; or (3) duplicate articles.

2.3. Data Extraction and Analysis. We extracted the data including the author (nationality, affiliation, and component), sample size, characteristics of the participant (patients or the health, age, gender, race, handedness, emotional state, acupuncture experience, and accompanying symptoms), neuroimaging technology, acupuncture intervention (method of intervention, manipulation procedure, Deqi/needle sensation, and acupuncturist), and ethical review. The data analysis was conducted after data extraction.

\section{Results}

$168[7,10-176]$ original articles were included in this study.

Most of the studies were conducted in China (80 studies) $[10,11,13,14,16,18-24,26,27,29-31,33-36,43-46,48,51$, $53,54,56,58-66,68-70,72-75,77,78,83,84,86,87,89,90$, 93, 95, 97, 99-101, 104, 111, 113, 115, 123, 137, 138, 142, 144$147,154,159,161-166]$ and in USA (40 studies) $[15,28,37$, $38,42,57,70,71,76,80,88,91,94,96,105-107,118-120,124-$ $127,129-131,133-136,140,141,148,151,152,155,156,158,174]$. The investigators in Korea (16 studies) [7, 47, 49, 52, 55, $82,85,98,102,109,112,114,116,117,122,153$ ], Taiwan (6

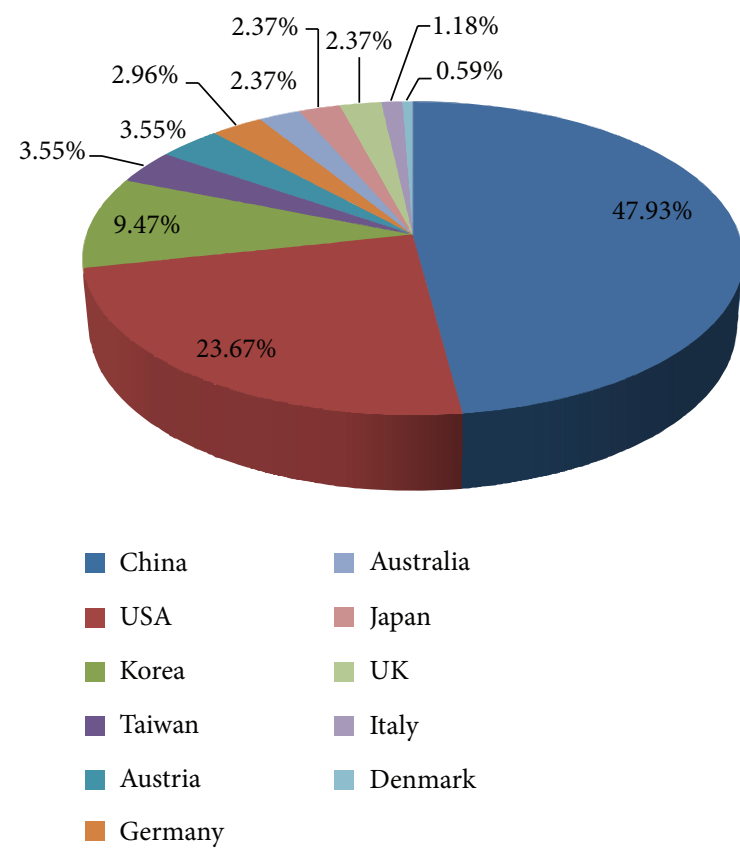

FIGURE 1: The nationality distribution of acupuncture-neuroimaging studies.

studies) $[79,110,128,170,171,175]$, Austria (6 studies) [132, $139,150,160,168,176]$, Germany (5 studies) [32, 50, 157, 167, 169], Australia (4 studies) [40, 41, 92, 121], Japan (4 studies) $[39,108,149,173]$, UK (4 studies) [17, 67, 81, 103], Italy (2 studies) [25, 172], and Denmark (1 study) [143] also published articles on acupuncture-neuroimaging (Figure 1). 60 studies $[16,19,23,25,26,37,38,42,45,46,55,56,60,62,65,67,70-$ $72,75,78,81,87,88,90,93,97,100,101,104,106,107,110,111$, $113-115,117-121,123,126-129,132,134,137,142,145-147,150$, $157,160,162,168,175]$ were performed with the cooperation of more than two countries.

3.1. Sample Size. The average sample size of these studies was 15 participants per group. For the studies performed on patients, the average sample size was 16 participants per group, while the maximal and minimal sample sizes per group were 55 participants and 1 participant, respectively. For those performed on healthy subjects, the average sample size was 14 per group, and the maximal and minimal sample sizes per group were 48 participants and 1 participant, respectively.

\subsection{The Status of Participants}

3.2.1. Classification of Participants. 122 studies [7, 11-13, 15$17,24,25,30-33,35,36,39,41-45,50,53-57,63,64,66-$ $70,72-76,78-83,85-100,102-104,106,107,109-111,113-$ $130,132,135,136,140,143,144,147-176]$ were performed on healthy subjects. 25 studies were $[10,26-29,34,38,49,51,58-$ $60,62,65,71,84,101,105,108,112,134,137,139,142,145]$ performed on patients. 21 studies $[14,18-23,37,40,46-$ $48,52,61,77,131,133,138,141,146,165]$ recruited both healthy subjects and patients. 25 kinds of diseases were involved in these studies (Table 1). 19 studies $[10,14,18,19,29,34,35$, 
TABLE 1: The diseases involved in acupuncture-neuroimaging studies.

\begin{tabular}{|c|c|c|}
\hline Category & Disease & Number of studies \\
\hline \multirow{8}{*}{ Neurology } & Stroke & 12 studies \\
\hline & Alzheimer's disease & 2 studies \\
\hline & Bell's palsy & 2 studies \\
\hline & Mild cognitive impairment & 2 studies \\
\hline & Parkinson’s disease & 2 studies \\
\hline & Vascular aphasia & 1 study \\
\hline & Carpal tunnel syndrome & 5 studies \\
\hline & Migraine & 2 studies \\
\hline \multirow{4}{*}{ Pain } & Chronic low back pain & 1 study \\
\hline & Fibromyalgia & 1 study \\
\hline & Chronic knee osteoarthritis pain & 1 study \\
\hline & Musculoskeletal disease & 1 study \\
\hline \multirow{3}{*}{ Psychonosology } & Depression & 2 studies \\
\hline & Heavy smoker & 1 study \\
\hline & Heroin addicts & 1 study \\
\hline \multirow{3}{*}{ Gastroenterology } & Functional diarrhea & 1 study \\
\hline & Irritable bowel syndrome-diarrhea & 2 studies \\
\hline & Functional dyspepsia & 1 study \\
\hline \multirow{3}{*}{ Pediatrics } & Childhood autism & 1 study \\
\hline & Children with visual disorder & 1 study \\
\hline & Children with a severe type of cerebral palsy & 1 study \\
\hline Rheumatology & Rheumatoid arthritis & 1 study \\
\hline Dermatology & Atopic dermatitis & 1 study \\
\hline Myopia & Myopia & 1 study \\
\hline
\end{tabular}

$40,46,51,52,59,62,65,77,84,112,134,146]$ classified the subtypes of diseases.

3.2.2. Age. 100 studies $[7,10,16-19,23,24,26,27,30,34,35$, $39-42,44-48,51-54,57,59,60,62,63,65,69-74,76,77,80-$ $82,84,85,87,89,92,97,98,101-103,105,107-109,112,114$, $116,117,120-122,124,125,129,131-135,137,139,141-145,148-$ $153,157,158,160,162,164,166-168,171-176]$ described the age range of participants. For the healthy subjects, the average age range was 18.3 years old, and the maximal age range was 62 , while the minimal age range was 3 . For the patients, the average age range was 29 years old, and the maximal age range was 57 , while the minimal age range was 6 . Taking studies on the stroke for instance, the maximal age range of the stroke patients was 52 , while the minimal age range was 7. Furthermore, 66 studies [11, 13-15, 20-22, 25, 28, 29, 31$33,36-38,43,49,50,55,56,58,61,64,66-68,75,78,79,83$, $86,88,90,91,93,95,96,99,100,104,106,110,111,113,115,118$, $119,123,126-128,130,136,138,140,146,147,154-156,159,161$, $163,169,176]$ described the average age of participants. Three studies $[94,163,170]$ did not mention the age of participants.

3.2.3. Gender. 159 studies [7, 10-26, 28-79, 81-93, 95-114, $116-123,125-131,133-151,153-169,172-176]$ described the gender of the participants (56.7\% male and $43.3 \%$ female).
Nine studies $[27,80,94,115,124,132,152,170,171]$ did not mention the gender of the participants.

3.2.4. Race and Handedness. 14 studies $[66,75,87,90,99,105$, $115,126,135,148,151,164,167,174]$ described and restricted the race of participants. $136[10-24,26,28,30-36,39-56,58$, 59, 61-80, 83-87, 89-93, 95, 96, 98-100, 103-107, 109-111, 113$115,117-131,133,135-138,140-142,144,146-149,151-157,159$, $162-164,166,168,169,171,173-175]$ studies asked for the righthand participants in inclusion criteria.

3.2.5. Emotional State. The psychological assessment on the participants was performed in 4 studies [21, 31, 46, 92, 93]. The self-rating depression scale (SDS) and the self-rating anxiety scale (SAS) were used in 2 studies $[31,46]$. The Beck Depression Inventory (BDI) [92] and the State Trait Anxiety Inventory (STAI) [93] were used in 1 study, respectively. Nine studies [19-22, 24, 65, 76, 92, 146] have excluded the participants with claustrophobia.

3.2.6. Accompanying Symptoms. 38 studies $[11,13,15,21,31$, $36,42,43,46,54,57,64,65,68,73,76,78,81,87,93,100$, $102,104,106,110-121,123,128,133,135,141,148,151,153,156$, $158,165,174]$ excluded the participants with head trauma, and some studies $[24,46,54,73,100,121,122]$ excluded the 


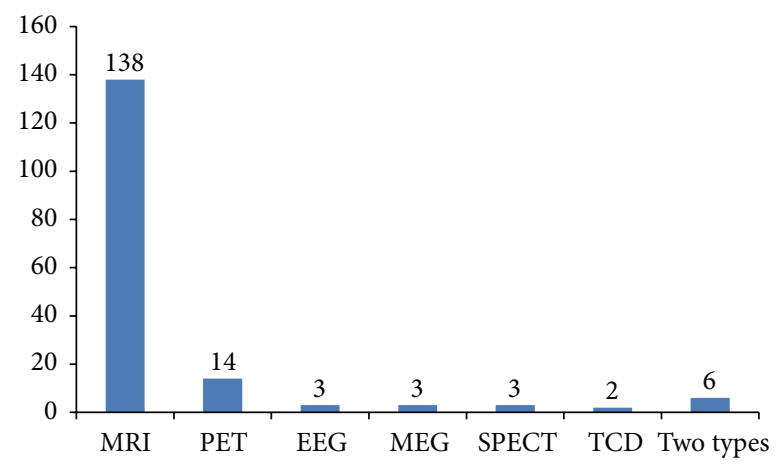

Figure 2: The techniques used in acupuncture-neuroimaging studies. MRI: Magnetic Resonance Imaging, PET: Positron Emission Tomography, EEG: electroencephalography, MEG: magnetoencephalography, SPECT: Single-Photon Emission Computed Tomography, and TCD: Transcranial Doppler.

participants suffering from pain (including headache and dysmenorrhea).

3.2.7. Acupuncture Experience. 81 articles [13-16, 18, 22, 24, $26,28,29,31,33-35,37,38,42,51,54-59,63,64,67,68,70$, $71,73,75,78,83,85-87,89,90,92,93,95,96,99,101,103-$ $106,108,111,113-115,117-121,123,127,130,135,138,140$, $144,147,148,151-153,156-158,162,166-169,174]$ described the acupuncture experience of participants. Among these articles, 73 articles $[12-16,18,22,28,29,31,33-35,37,38$, $42,51,55,57-59,63,64,67,68,70,71,73,75,78,83,85-$ $87,89,90,93,95,96,99,101,103-106,108,111,113-115,117-$ $121,123,127,130,135,138,140,144,147,148,151-153,157,158$, 166-169] described the participants as acupuncture naive.

3.3. Neuroimaging Technology. 137 studies $[7,11,12,14-26,28$, $29,31-42,44-50,52,53,55-61,63,64,66,68-79,84-87,89-$ $101,103,104,106,107,109-115,117-120,122,123,125-129,131-$ $136,138-141,144,146-159,161,162,164,166-168,170,171,173-$ 175] used fMRI (82.14\%) to investigate the cerebral responses to acupuncture stimulation. Six studies $[43,80,88,116,130$, 160] used the combination of two imaging technologies. The application of the techniques in acupuncture-neuroimaging studies was shown in Figure 2.

\subsection{Acupuncture Intervention}

3.4.1. Method of Intervention. 111 studies [7, 10, 12-14, 16$26,28,29,31-34,36,39,42,43,46-59,61,63,64,66-68,75$, $78,82,83,85-88,90,91,93-95,97-100,102-106,108-114,125-$ $129,132,135-139,142,144,145,148,149,151,153,154,156$, $157,163-165,167,172,174-176]$ chose manual acupuncture as intervention method. 32 studies $[27,37,38,44,60,62,65$, $69,70,72,76,77,80,84,89,96,101,107,115-117,124,140$, $146,152,159,162,166,169-171,173]$ chose electroacupuncture as intervention method. Besides, the transcutaneous electric acupoint stimulation was performed in 6 studies $[45,73,74$, $81,141,143]$, the laser acupuncture in 6 studies $[40,79,92,150$, $160,168]$, heat stimulation on acupoints in 2 studies $[147,155]$,
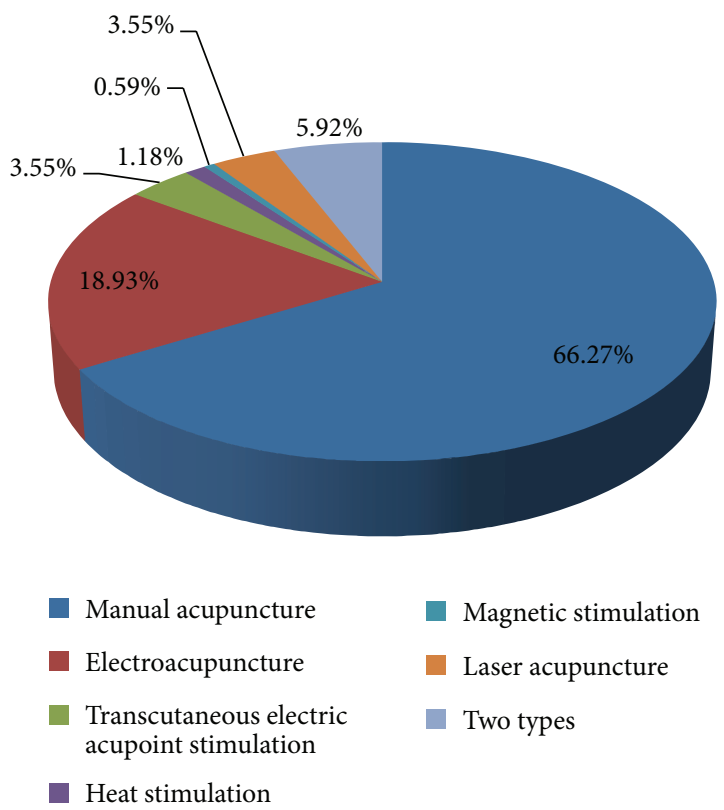

FIGURE 3: The acupuncture methods used in acupunctureneuroimaging studies.

and the magnetic stimulation on acupoints in 1 study [30]. There were 10 studies $[11,15,35,41,71,131,133,134,158,161]$ using at least two types of acupuncture methods (Figure 3).

3.4.2. Manipulation Procedure. 134 articles [10-20, 22, 24, 26, 27, 29, 30, 34-39, 41, 42, 46-52, 54-70, 72, 73, 75-130, 132, $133,135-138,142$, 144-146, 148, 151-154, 156-158, 163, 167-170, $172,174-176]$ have described the manipulation procedure of acupuncture.

3.4.3. Deqi (Needle Sensation). 82 studies $[10,15,16,22,23$, $26,28,29,34,35,37,38,41-47,50,54,56,57,64,68,69,72,73$, 75-77, 80, 87, 89-91, 93-96, 98-101, 103, 105-111, 114, 115, 117, $118,120-124,127,130,133,135-138,140,144,146,148,153,157$, $158,166-168,172,174-176]$ required Deqi (needle sensation) during acupuncture stimulation.

56 studies $[10,14-18,28,35,38,42,43,50,53,55,57,58,61$, $64,66,68,69,71,73,75-77,87,89-91,93-96,99-101,103,104$, $106-111,115,117,120,124,127-130,140,166,169]$ have evaluated needle sensation after acupuncture stimulation. The 10-point Visual Analogue Scale (VAS), the Massachusetts General Hospital Acupuncture Sensation Scale (MASS), the Subject Acupuncture Sensation Scale (SASS), the 6-point Likert scale, the Park questionnaire, the Psychophysical Rating of Needling Sensation, and the Needle Sensation Questionnaire (NSQ) were used to evaluate the needle sensation (Figure 4).

3.4.4. Qualification of Acupuncturists. 99 articles [12, 14-19, 22-24, 26, 28, 29, 31-42, 44, 46-50, 52, 54-61, 63, 64, 66, $67,69,71,72,75,78,80,82-84,86,87,89-91,93-98,100-$ $104,106,108-112,114-117,119-124,126-129,133,135,139,140$, $142,144,150,158,166,174]$ have mentioned the qualification of acupuncturists. 


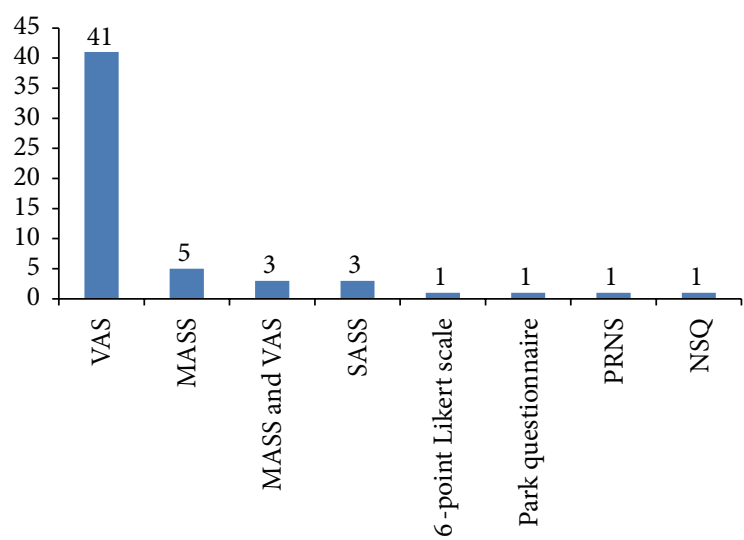

FIgURE 4: The scales/questionnaire used in needle sensation evaluation. VAS: 10-point Visual Analogue Scale, MASS: Massachusetts General Hospital Acupuncture Sensation Scale, SASS: Subject Acupuncture Sensation Scale, PRNS: Psychophysical Rating of Needling Sensation, and NSQ: Needle Sensation Questionnaire.

3.5. The Ethical Review. 139 studies [10-18, 20-29, 31-36, 38$45,47-58,60,63-79,81-86,88,90-93,96-107,109-115,117-$ $121,123-125,127,128,130-133,135,136,138-148,150-156,158-$ $162,164,166-168,172,174,175]$ have mentioned the ethical review in the study.

\section{Discussion}

Owning to the complexity of the brain function and the diversity of acupuncture manipulations, the different or even reversed results occurring in similar acupunctureneuroimaging studies become a common phenomenon. Seeking reasonable and practical methods is essential to improve the reproducibility and reliability of results in acupuncture-neuroimaging studies. Based on the open published literatures, this study analyzed the status of quality control in acupuncture-neuroimaging study for the first time and tried to provide some new ideas for future studies.

4.1. Sample Size. The appropriate sample size is important for designing an acupuncture-neuroimaging study. Bigger sample size increases statistical power because the standard error of the mean decreases by the square root of number $(N)$. Due to the potential radioactivity (PET/SPECT) and the costs of imaging, the sample size in most of the neuroimaging studies was small. Some investigators suggested that 12 to 15 subjects per group could get statistical power in fMRI studies $[177,178]$. Others held that the method should ensure large sample size to use rigorous corrections for multiple tests [179]. In this study, we found that the average sample size was 15 participants per group, and the average sample size for patients was slightly bigger than that for healthy subjects (16 versus 14 per group). Nowadays, most investigators agreed that, to achieve the stable statistical power, bigger sample size (at least 20 participants per group) was needed in the future acupuncture-neuroimaging study [180].
4.2. The Selection of Participants. The rigorous inclusion and exclusion criteria, as important guaranty for the homogeneity of the participants, are of great significance in the quality control of clinical trial.

4.2.1. Classification of Participants. This study indicated that the majority of neuroimaging studies (72.78\%) were performed on healthy subjects. It might be a reason for the inconsistent results. Because the traditional Chinese acupuncture theory holds that acupuncture treatment focuses on strengthening the body resistance to removing pathogenic factors and restoring the balance of Yin and Yang, the efficacy of acupuncture treatment is specific to the pathological conditions (imbalance of Yin and Yang), not the physiological state (Yin and Yang in equilibrium). So during the pathological conditions, the actions of acupoints are disease-oriented, while in the physiological state, the acupoint keeps in silence and the actions of acupoints lack orientation. In this case, patient is the better choice for acupuncture-neuroimaging studies.

In this study, we found that there was a preponderance of nervous system disorders such as stroke among the diseases involved in acupuncture-neuroimaging studies. The result indicated that acupuncture stimulation promoted the action of neural rehabilitation and its mechanism is a focus of acupuncture study. Furthermore, we noticed that some studies were performed on functional disorders such as functional dyspepsia and irritable bowel syndrome [65, 101]. As we know, regulating functional disorder is the advantage of acupuncture, so functional disorder might be a new approach in future studies.

Moreover, the subtypes of a disease should be taken into consideration when you choose patients as the participants in neuroimaging study for the patients with different subtypes might have functional or/and structural differences in brain. For example, schizophrenic subjects with predominantly negative symptoms have greater metabolic abnormalities than subjects with predominantly positive symptoms [181]. So, in acupuncture-neuroimaging study, it is better to choose the same subtype of a disease to ensure the homogeneity of participants.

4.2.2. Demographic Characteristics of Participants. Some demographic characteristics of participants including age, gender, race, and handedness should be defined in the inclusion criteria.

The changes of cerebral function and structure come with age. Some studies indicated that the cerebral glucose metabolism decreased unevenly and brain tissues began aging after 40 years old [182, 183]. Older age directly correlated with reduced gray matter volume in bilateral rostral and right dorsal ACC [184]. So the age range of participants should not be ignored in neuroimaging studies. However we found that most of these studies (101 studies) described the age range of participants, that the average age range of healthy subjects was 18.3 years old, and that the average age range of patients was 29 years old. Even in some studies, the age range 
was more than 50 years old. It is better to keep the age range within 20 years to reduce the effect of outlier.

The functional and structural differences in human brain induced by handedness have long been investigated [185188], although the mechanism remains unclear. So the majority of the current studies (137 studies) choose right-hand participants.

Furthermore, gender differences of the human brain are an important issue in neuroimaging studies. It has been identified that gender has significant influence on the regional neuronal activity $[189,190]$ and brain structure [191]. Race differences may lead to differences of brain function and structure. For example, it is reported that brain size varies by race [192]. In this study, we found that 14 studies $(8.33 \%)$ described and restricted the race of the participants. Taking gender and race as covariates is needed when designing acupuncture-neuroimaging experiments.

4.2.3. Emotional State. The psychological factors have significant influence on the function and structure of human brain. For example, Drevets et al. have found an area of abnormally decreased activity in the prefrontal cortex ventral to the genu of the corpus callosum in both unipolar depressives and bipolar depressives [193]. Our study shows that only 4 articles described the psychological assessment performed on the participants; more attention should be paid to the emotional state of subjects during the inclusion and data analysis in future studies, except for the study which focuses on the mechanism of acupuncture treating for psychological disorders.

Furthermore, our study demonstrated that participants with claustrophobia have been excluded in 9 studies. Claustrophobia is a phobic disorder which will cause panic, fear, or anxiety in the confined space. Scanning cannot be accomplished when it is performed on a participant with claustrophobia. So the participants with claustrophobia should be excluded in acupuncture-neuroimaging studies.

4.2.4. Menstrual Period. In this study, we found that female participants were involved in 145 studies. Recently, some studies performed on healthy subjects indicated the cerebral functional and structural changes in menstrual period. For example, Veldhuijzen et al. [194] found that the pain-related cerebral activation varied significantly across the menstrual cycle. Hagemann et al. [195] found a significant gray matter volume peak and cerebral spinal fluid loss at the time of ovulation in females. So, for female participants, scanning should be performed during the same physiological period to avoid the possible changes in brain size and activity in menstrual cycles.

4.2.5. Accompanying Symptoms/Disorders. The accompanying symptoms/disorders such as head trauma, pain (including headache and dysmenorrhea), and insomnia should be excluded as possible as we could considering their influence on the neuroimaging data. Tu et al. [196, 197] found that abnormal gray matter volume changes are presented in primary dysmenorrhea patients even in the absence of pain.
Furthermore, some investigators held that blood coagulation disorders should be excluded in acupuncture studies [6].

4.2.6. Acupuncture Experience. Some studies have reported the significant differences in cerebral response between the participant with acupuncture experience and the participant without acupuncture experience [198]. In our study, we found that participants in $44.04 \%$ of the studies were acupuncture naive. To ensure the consistency of the baseline of the participants and the comparability of consequence, the acupuncture experience of participants should be taken into consideration.

4.3. Image Technology. Among the neuroimaging technologies, fMRI (82.14\%) was most commonly used in the acupuncture-neuroimaging studies. But we also found that multimodel imaging techniques became a new trend in acupuncture-neuroimaging studies for their significant advantages in improving spatial/temporal resolutions and lowing noise.

\subsection{Acupuncture Intervention}

4.4.1. Method of Intervention. We found that, during 1995 to $2014,66.27 \%$ studies have used manual acupuncture as intervention method, and $18.93 \%$ studies have used the electroacupuncture as intervention method. Among those manual acupuncture studies, $78.57 \%$ studies have described the needle manipulation. During 2005-2014, the majority of acupuncture-neuroimaging studies (68.71\%) still used manual acupuncture as intervention method, and $17.01 \%$ studies used the electroacupuncture as intervention method. Among the manual acupuncture studies, 79.21\% studies have described the needle manipulation. The results indicated that (1) although the stimulation of manual acupuncture is hard to be quantified for the individual differences of manipulation induced by different practitioners, manual acupuncture, as the traditional acupuncture intervention, is easier to be accepted by investigators and (2) the majority of these studies with manual acupuncture treatment describe the acupuncture manipulation including sterilization, the angle and depth of needle insertion, and the duration of retaining needle to ensure consistency of acupuncture treatment. Considering the influence of different manipulation results, we should not allocate too many acupuncturists in one neuroimaging study. In order to ensure the accuracy of the results, it is better to perform acupuncture manipulation with one acupuncturist.

Meanwhile, transcutaneous electric acupoint stimulation, magnetic stimulation, heat stimulation, and laser acupuncture were used in some neuroimaging studies. The results indicated that not only manual acupuncture and electroacupuncture, but also other acupuncture-related interventions attract increasing interests of investigators. In the future, more attention should be paid to those acupuncture methods which have not or seldom been touched such as ear acupuncture, abdominal acupuncture, and wrist and ankle acupuncture.

4.4.2. Qualification of Acupuncturist and Operation Procedure. The qualification of acupuncturist and operation procedure 
is important in quality control of acupuncture trial. In our study, $59.5 \%$ of the studies have mentioned the qualification of acupuncturists and $79.88 \%$ of the studies have described the manipulation procedure of acupuncture. For the defined influence of the qualification of acupuncturist and manipulation procedure on clinical efficacy, the needling details including numbers of needle, depth of insertion, elicited response, and needle retention time and the background of practitioners including the duration of relevant training, length of clinical experience, and details of expertise in treating the specific condition being evaluated as well as any other experience that may be relevant to the trial should be reported according to the standards for reporting interventions in controlled trials of acupuncture (The STRICTA Recommendations) [199].

4.4.3. Deqi (Needle Sensation) and Evaluation of Sensation. Deqi (needle sensation) plays an important role in acupuncture efficacy. Clinical trials have demonstrated that acupuncture with needle sensation was superior to acupuncture without needle sensation for analgesia [200] and paralysis [201]. A neuroimaging study [54] also showed the significant differences of cerebral responses under the Deqi and nonDeqi condition. So it is important to record the Deqi sensation in acupuncture studies.

In this study, we found that the questionnaire-based forms such as 10-point VAS, MASS, SASS, Park questionnaire, Psychophysical Rating of Needling Sensation, and NSQ were used to assess the needle sensation in acupunctureneuroimaging studies. Among them, 10-point VAS was the most commonly used (68.3\%). However, the liabilities and validities of some specific or nonspecific questionnaires/scales for needle sensation need further investigation.

4.5. The Author Nationality and Ethical Review. In this study, we found that $63.7 \%$ of the studies were accomplished by the cooperation of more than two countries. The international cooperation improved the study level and quality control in some degree. To get more international recognition and perfecting research, the acupuncture-neuroimaging studies need more international cooperation. Furthermore, ethics has got growing attention by the researchers. The interests of the participants should be taken in the first place. The ethics was an essential component which should be considered during the whole acupuncture-neuroimaging studies.

In conclusion, to improve the reproducibility and reliability of the acupuncture-neuroimaging studies, more attention should be paid to the quality control including sample size, participants screening, and acupuncture manipulations in future studies. A practical and standard quality control criterion should be developed to improve the acupunctureneuroimaging studies.

\section{Disclosure}

Ke Qiu, Miaomiao Jing, and Ruirui Sun are co-first authors and contributed equally to this paper.

\section{Competing Interests}

The authors declare that they have no competing interests.

\section{Acknowledgments}

This study was supported by the National Natural Science Foundation of China (no. 81473602), the State Key Program for Basic Research of China (973 Program, no. 2012CB518501), the Education Ministry's New Century Excellent Talents Supporting Plan, the Special Fund for the Authors Who Win the 100 Top Doctoral Dissertations Award of China (no. 2014084), and the Sichuan Youth Science \& Technology Foundation (no. 15QNJJ0008).

\section{References}

[1] D. L. Diehl, G. Kaplan, I. Coulter, D. Glik, and E. L. Hurwitz, "Use of acupuncture by American physicians," Journal of Alternative and Complementary Medicine, vol. 3, no. 2, pp. 119-126, 1997.

[2] D. M. Eisemberg, R. C. Kessler, C. Foster et al., "Unconventional medicine in the United States," The New England Journal of Medicine, vol. 328, pp. 246-252, 1993.

[3] D. M. Elsenberg, R. B. Davis, and S. C. Ethmer, "Trend in alternative medicines use in the United States," The Journal of the American Medical Association, vol. 280, pp. 1569-1575, 1990.

[4] Z. Yu, X. Cao, Y. Xia et al., "Electroacupuncture stimulation at CV12 inhibits gastric motility via TRPV1 receptor," Evidence Based Complementary and Alternative Medicine, vol. 2013, Article ID 294789, 6 pages, 2013.

[5] J. Kerr Grieve, S. Flucker, and J. O’Riordan, "Acupuncture is an effective treatment for pain and other mssymptoms," Journal of Neurology, Neurosurgery \& Psychiatry, vol. 84, article e2, 2013.

[6] J.-S. Han, "Acupuncture: neuropeptide release produced by electrical stimulation of different frequencies," Trends in Neurosciences, vol. 26, no. 1, pp. 17-22, 2003.

[7] Z. H. Cho, S. C. Chung, J. P. Jones et al., "New findings of the correlation between acupoints and corresponding brain cortices using functional MRI," Proceedings of the National Academy of Sciences of the United States of America, vol. 95, no. 5, pp. 2670-2673, 1998.

[8] F. Zeng, X.-G. Liu, Y. Tang, and F.-R. Liang, "Application of PET-CT technique to the research on central mechanism of acupuncture effects," Zhen Ci Yan Jiu, vol. 33, no. 4, pp. 284286, 2008.

[9] Z.-H. Cho, T. D. Oleson, D. Alimi, and R. C. Niemtzow, "Acupuncture: the search for biologic evidence with functional magnetic resonance imaging and positron emission tomography techniques," Journal of Alternative and Complementary Medicine, vol. 8, no. 4, pp. 399-401, 2002.

[10] J. Yang, F. Zeng, Y. Feng et al., "A PET-CT study on the specificity of acupoints through acupuncture treatment in migraine patients," BMC Complementary and Alternative Medicine, vol. 12, article 123, 2012.

[11] X.-J. Ren, H.-Y. Chen, B.-G. Wang et al., "Regional homogeneity analysis on acupoint specificity with resting-state functional magnetic resonance imaging," Chinese Medical Journal, vol. 125, no. 9, pp. 1627-1632, 2012. 
[12] M. Dong, W. Qin, J. Sun et al., “Tempo-spatial analysis of visionrelated acupoint specificity in the occipital lobe using fMRI: an ICA study," Brain Research, vol. 1436, pp. 34-42, 2012.

[13] Y. Feng, L. Bai, W. Zhang et al., "Investigation of acupoint specificity by whole brain functional connectivity analysis from fMRI data," in Proceedings of the 33rd Annual International Conference of the IEEE Engineering in Medicine and Biology Society (EMBS '11), pp. 2784-2787, Boston, Mass, USA, August 2011.

[14] Z. Liu, W. Wei, L. Bai et al., "Exploring the patterns of acupuncture on mild cognitive impairment patients using regional homogeneity," PLoS ONE, vol. 9, no. 6, Article ID e99335, 2014.

[15] J. Kong, T. J. Kaptchuk, J. M. Webb et al., "Functional neuroanatomical investigation of vision-related acupuncture point specificity-a multisession fMRI study," Human Brain Mapping, vol. 30, no. 1, pp. 38-46, 2009.

[16] J. Fang, Z. Jin, Y. Wang et al., "The salient characteristics of the central effects of acupuncture needling: limbic-paralimbicneocortical network modulation," Human Brain Mapping, vol. 30, no. 4, pp. 1196-1206, 2009.

[17] H. MacPherson, G. Green, A. Nevado et al., "Brain imaging of acupuncture: comparing superficial with deep needling," Neuroscience Letters, vol. 434, no. 1, pp. 144-149, 2008.

[18] Z. Xie, F. Cui, Y. Zou, and L. Bai, "Acupuncture enhances effective connectivity between cerebellum and primary sensorimotor cortex in patients with stable recovery stroke," EvidenceBased Complementary and Alternative Medicine, vol. 2014, Article ID 603909, 9 pages, 2014.

[19] L. Bai, Y. Tao, D. Wang et al., "Acupuncture induces timedependent remodelling brain network on the stable somatosensory first-ever stroke patients: combining diffusion tensor and functional MR imaging," Evidence-based Complementary and Alternative Medicine, vol. 2014, Article ID 740480, 7 pages, 2014.

[20] Z. Wang, P. Liang, Z. Zhao et al., "Acupuncture modulates resting state hippocampal functional connectivity in Alzheimer disease," PLoS ONE, vol. 9, no. 3, Article ID e91160, 2014.

[21] P. Liang, Z. Wang, T. Qian, and K. Li, "Acupuncture stimulation of Taichong (Liv3) and Hegu (LI4) modulates the default mode network activity in Alzheimer's disease," American Journal of Alzheimer's Disease and Other Dementias, vol. 29, no. 8, pp. 739$748,2014$.

[22] J. Li, J.-H. Zhang, T. Yi, W.-J. Tang, S.-W. Wang, and J.-C. Dong, "Acupuncture treatment of chronic low back pain reverses an abnormal brain default mode network in correlation with clinical pain relief," Acupuncture in Medicine, vol. 32, no. 2, pp. 102-108, 2014.

[23] X. He, Y. Zhu, C. Li et al., "Acupuncture-induced changes in functional connectivity of the primary somatosensory cortex varied with pathological stages of Bell's palsy," NeuroReport, vol. 25, no. 14, pp. 1162-1168, 2014.

[24] C. Wu, S. Qu, J. Zhang et al., "Correlation between the effects of acupuncture at Taichong (LR3) and functional brain areas: a resting-state functional magnetic resonance imaging study using true versus sham acupuncture," Evidence-Based Complementary and Alternative Medicine, vol. 2014, Article ID 729091, 7 pages, 2014.

[25] M. Romoli, G. Allais, G. Airola et al., "Ear acupuncture and fMRI: a pilot study for assessing the specificity of auricular points," Neurological Sciences, vol. 35, no. 1, pp. S189-S193, 2014.

[26] L. Zhao, J. Liu, F. Zhang et al., "Effects of long-term acupuncture treatment on resting-state brain activity in migraine patients: a randomized controlled trial on active acupoints and inactive acupoints," PLoS ONE, vol. 9, no. 6, Article ID e99538, 2014.

[27] Z.-Q. Zhao, S.-W. Jia, S. Hu, and W. Sun, "Evaluating the effectiveness of electro-acupuncture as a treatment for childhood autism using single photon emission computed tomography," Chinese Journal of Integrative Medicine, vol. 20, no. 1, pp. 19-23, 2014.

[28] J. A. Hashmi, J. Kong, R. Spaeth, S. Khan, T. J. Kaptchuk, and R. L. Gollub, "Functional network architecture predicts psychologically mediated analgesia related to treatment in chronic knee pain patients," Journal of Neuroscience, vol. 34, no. 11, pp. 3924-3936, 2014.

[29] J. Chen, J. Wang, Y. Huang et al., "Modulatory effect of acupuncture at Waiguan (TE5) on the functional connectivity of the central nervous system of patients with ischemic stroke in the left basal ganglia," PLoS ONE, vol. 9, no. 6, Article ID e96777, 2014.

[30] L. Guo, Y. Wang, H. Yu, N. Yin, and Y. Li, "Study of brain functional network based on sample entropy of EEG under magnetic stimulation at PC6 acupoint," Bio-Medical Materials and Engineering, vol. 24, no. 1, pp. 1063-1069, 2014.

[31] L. Zhao, W. Qin, J. X. Liu et al., "Two sets of acupoint combination of similar functions engage shared neural representation: a functional magnetic resonance imaging study," Chinese Journal of Integrative Medicine, vol. 20, no. 3, pp. 184-193, 2014.

[32] T. I. Usichenko, T. Wesolowski, and M. Lotze, "Verum and sham acupuncture exert distinct cerebral activation in pain processing areas: a crossover fMRI investigation in healthy volunteers," Brain Imaging and Behavior, vol. 9, no. 2, pp. 236244, 2014.

[33] H. Cheng, H. Yan, L.-J. Bai, and B.-G. Wang, "Exploration of whole brain networks modulated by acupuncture at analgesia acupoint ST36 using scale-specific wavelet correlation analysis," Chinese Medical Journal, vol. 126, no. 13, pp. 2459-2464, 2013.

[34] Y. Huang, J.-Q. Chen, X.-S. Lai et al., "Lateralisation of cerebral response to active acupuncture in patients with unilateral ischaemic stroke: an fMRI study," Acupuncture in Medicine, vol. 31, no. 3, pp. 290-296, 2013.

[35] Y. Jiang, H. Wang, Z. Liu et al., "Manipulation of and sustained effects on the human brain induced by different modalities of acupuncture: an fMRI study," PLoS ONE, vol. 8, no. 6, Article ID e66815, 2013.

[36] J. Liu, J. Nan, S. Xiong, G. Li, W. Qin, and J. Tian, "Additional evidence for the sustained effect of acupuncture at the visionrelated acupuncture point, GB37," Acupuncture in Medicine, vol. 31, no. 2, pp. 185-194, 2013.

[37] Y. Maeda, N. Kettner, J. Lee et al., "Acupuncture evoked response in contralateral somatosensory cortex reflects peripheral nerve pathology of carpal tunnel syndrome," Medical Acupuncture, vol. 25, no. 4, pp. 275-284, 2013.

[38] Y. Maeda, N. Kettner, J. Lee et al., "Acupuncture-evoked response in somatosensory and prefrontal cortices predicts immediate pain reduction in carpal tunnel syndrome," Evidence-Based Complementary and Alternative Medicine, vol. 2013, Article ID 795906, 13 pages, 2013.

[39] T. Murase, M. Umeda, M. Fukunaga, C. Tanaka, and A. T. Higuchi, "Deconvolution analyses with tent functions reveal delayed and long-sustained increases of BOLD signals with acupuncture stimulation," Magnetic Resonance in Medical Sciences, vol. 12, no. 2, pp. 121-127, 2013.

[40] I. Quah-Smith, C. Suo, M. A. Williams, and P. S. Sachdev, "The antidepressant effect of laser acupuncture: a comparison of the 
resting brain's default mode network in healthy and depressed subjects during functional magnetic resonance imaging," Medical Acupuncture, vol. 25, no. 2, pp. 124-133, 2013.

[41] I. Quah-Smith, M. A. Williams, T. Lundeberg, C. Suo, and P. Sachdev, "Differential brain effects of laser and needle acupuncture at LR8 using functional MRI," Acupuncture in Medicine, vol. 31, no. 3, pp. 282-289, 2013.

[42] X. Wang, S.-T. Chan, J. Fang et al., "Neural encoding of acupuncture needling sensations: evidence from a fMRI study," Evidence-Based Complementary and Alternative Medicine, vol. 2013, Article ID 483105, 15 pages, 2013.

[43] Y. You, L. Bai, R. Dai et al., "Altered hub configurations within default mode network following acupuncture at ST36: a multimodal investigation combining fMRI and MEG," PLoS ONE, vol. 8, no. 5, Article ID e64509, 2013.

[44] G. Zhang, S. Qu, Y. Zheng et al., "Key regions of the cerebral network are altered after electro acupuncture at the Baihui (GV20) and Yintang acupuncture points in healthy volunteers: an analysis based on resting fcMRI," Acupuncture in Medicine, vol. 31, no. 4, pp. 383-388, 2013.

[45] Y. Zhang, Y. Jiang, C. B. Glielmi et al., "Long-duration transcutaneous electric acupoint stimulation alters small-world brain functional networks," Magnetic Resonance Imaging, vol. 31, no. 7, pp. 1105-1111, 2013.

[46] S. Zhou, F. Zeng, J. Liu et al., "Influence of acupuncture stimulation on cerebral network in functional diarrhea," EvidenceBased Complementary and Alternative Medicine, vol. 2013, Article ID 975769, 9 pages, 2013.

[47] S.-Y. Cho, M. Kim, J. J. Sun et al., "A comparison of brain activity between healthy subjects and stroke patients on fMRI by acupuncture stimulation," Chinese Journal of Integrative Medicine, vol. 19, no. 4, pp. 269-276, 2013.

[48] C. Li, J. Yang, J. Sun et al., "Brain responses to acupuncture are probably dependent on the brain functional status," EvidenceBased Complementary and Alternative Medicine, vol. 2013, Article ID 175278, 14 pages, 2013.

[49] O.-S. Kang, S.-Y. Kim, G.-H. Jahng et al., "Neural substrates of acupuncture in the modulation of cravings induced by smoking-related visual cues: an FMRI study," Psychopharmacology, vol. 228, no. 1, pp. 119-127, 2013.

[50] F. Beissner, R. Deichmann, C. Henke, and K.-J. Bär, "Acupuncture-deep pain with an autonomic dimension?" NeuroImage, vol. 60, no. 1, pp. 653-660, 2012.

[51] Y. Huang, C. Tang, S. Wang et al., "Acupuncture regulates the glucose metabolism in cerebral functional regions in chronic stage ischemic stroke patients-a PET-CT cerebral functional imaging study," BMC Neuroscience, vol. 13, no. 1, article 75, 2012.

[52] S. Yeo, S. Lim, I.-H. Choe et al., "Acupuncture stimulation on gb34 activates neural responses associated with parkinson's disease," CNS Neuroscience and Therapeutics, vol. 18, no. 9, pp. 781-790, 2012.

[53] B. Liu, J. Chen, J. Wang et al., "Altered small-world efficiency of brain functional networks in acupuncture at ST36: a functional MRI study," PLoS ONE, vol. 7, no. 6, Article ID e39342, 2012.

[54] J.-R. Chen, G.-L. Li, G.-F. Zhang, Y. Huang, S.-X. Wang, and N. Lu, "Brain areas involved in acupuncture needling sensation of de qi: a single-photon emission computed tomography (SPECT) study," Acupuncture in Medicine, vol. 30, no. 4, pp. 316323, 2012.
[55] V. Napadow, J. Lee, J. Kim et al., "Brain correlates of phasic autonomic response to acupuncture stimulation: an eventrelated fMRI study," Human Brain Mapping, vol. 34, no. 10, pp. 2592-2606, 2013.

[56] G. Zhang, H. Yin, Y.-L. Zhou et al., "Capturing amplitude changes of low-frequency fluctuations in functional magnetic resonance imaging signal: a pilot acupuncture study on NeiGuan (PC6)," Journal of Alternative and Complementary Medicine, vol. 18, no. 4, pp. 387-393, 2012.

[57] J. D. Claunch, S.-T. Chan, E. E. Nixon et al., "Commonality and specificity of acupuncture action at three acupoints as evidenced by fMRI," American Journal of Chinese Medicine, vol. 40, no. 4, pp. 695-712, 2012.

[58] H. Liu, J. Xu, B. Shan et al., "Determining the precise cerebral response to acupuncture: an improved FMRI study," PLOS ONE, vol. 7, no. 11, Article ID e49154, 2012.

[59] Y. Shen, M. Li, R. Wei, and M. Lou, "Effect of acupuncture therapy for postponing wallerian degeneration of cerebral infarction as shown by diffusion tensor imaging," The Journal of Alternative and Complementary Medicine, vol. 18, no. 12, pp. 1154-1160, 2012.

[60] W. C. W. Chu, J. C. Y. Wu, D. T. W. Yew et al., "Does acupuncture therapy alter activation of neural pathway for pain perception in irritable bowel syndrome?: a comparative study of true and sham acupuncture using functional magnetic resonance imaging," Journal of Neurogastroenterology and Motility, vol. 18, no. 3, pp. 305-316, 2012.

[61] Y. Feng, L. Bai, Y. Ren et al., "FMRI connectivity analysis of acupuncture effects on the whole brain network in mild cognitive impairment patients," Magnetic Resonance Imaging, vol. 30, no. 5, pp. 672-682, 2012.

[62] Z. Fang, J. Ning, C. Xiong, and Y. Shulin, "Effects of electroacupuncture at head points on the function of cerebral motor areas in stroke patients: a pet study," Evidence-Based Complementary and Alternative Medicine, vol. 2012, Article ID 902413, 9 pages, 2012.

[63] S.-J. Chen, L. Meng, H. Yan et al., "Functional organization of complex brain networks modulated by acupuncture at different acupoints belonging to the same anatomic segment," Chinese Medical Journal, vol. 125, no. 15, pp. 2694-2700, 2012.

[64] J. Sun, W. Qin, L. Jin et al., "Impact of global normalization in fMRI acupuncture studies," Evidence-Based Complementary and Alternative Medicine, vol. 2012, Article ID 467061, 22 pages, 2012.

[65] F. Zeng, W. Qin, T. Ma et al., "Influence of acupuncture treatment on cerebral activity in functional dyspepsia patients and its relationship with efficacy," The American Journal of Gastroenterology, vol. 107, no. 8, pp. 1236-1247, 2012.

[66] C. Zhong, L. Bai, R. Dai et al., "Modulatory effects of acupuncture on resting-state networks: a functional MRI study combining independent component analysis and multivariate granger causality analysis," Journal of Magnetic Resonance Imaging, vol. 35, no. 3, pp. 572-581, 2012.

[67] U. R. Asghar Aziz, R. L. Johnson, W. Woods, G. G. Green, G. Lewith, and H. Macpherson, "Oscillatory neuronal dynamics associated with manual acupuncture: a magnetoencephalography study using beam forming analysis," Frontiers in Human Neuroscience, vol. 6, article 303, 2012. 
[68] J. Sun, Y. Zhu, L. Jin et al., "Partly separated activations in the spatial distribution between de-qi and sharp pain during acupuncture stimulation: an fMRI-based study," EvidenceBased Complementary and Alternative Medicine, vol. 2012, Article ID 934085, 11 pages, 2012.

[69] Y. Zheng, S. Qu, N. W. Wang et al., "Post-stimulation effect of electroacupuncture at Yintang (EX-HN3) and GV20 on cerebral functional regions in healthy volunteers: a resting functional MRI study," Acupuncture in Medicine, vol. 30, no. 4, pp. 307-315, 2012.

[70] Y. Zhang, C. B. Glielmi, Y. Jiang et al., "Simultaneous CBF and BOLD mapping of high frequency acupuncture induced brain activity," Neuroscience Letters, vol. 530, no. 1, pp. 12-17, 2012.

[71] V. Napadow, A. Li, M. L. Loggia et al., "The brain circuitry mediating antipruritic effects of acupuncture," Cerebral Cortex, vol. 24, no. 4, pp. 873-882, 2014.

[72] J. Fang, X. Wang, H. Liu et al., “The limbic-prefrontal network modulated by electroacupuncture at CV4 and CV12," EvidenceBased Complementary and Alternative Medicine, vol. 2012, Article ID 515893, 11 pages, 2012.

[73] Y. Jiang, Y. Hao, Y. Zhang et al., “Thirty minute transcutaneous electric acupoint stimulation modulates resting state brain activities: a perfusion and BOLD fMRI study," Brain Research, vol. 1457, pp. 13-25, 2012.

[74] R. Bao, P. Wei, K. Li et al., "Within-limb somatotopic organization in human SI and parietal operculum for the leg: an fMRI study," Brain Research, vol. 1445, pp. 30-39, 2012.

[75] W. Qin, L. Bai, J. Dai et al., “The temporal-spatial encoding of acupuncture effects in the brain," Molecular Pain, vol. 7, article 19, 2011.

[76] S. Shukla, A. Torossian, J.-R. Duann, and A. Leung, "The analgesic effect of electroacupuncture on acute thermal pain perception-a central neural correlate study with fMRI," Molecular Pain, vol. 7, article 45, 2011.

[77] G. Li and E. S. Yang, "An fMRI study of acupuncture-induced brain activation of aphasia stroke patients," Complementary Therapies in Medicine, vol. 19, supplement 1, pp. S49-S59, 2011.

[78] J. Liu, W. Qin, Q. Guo et al., "Divergent neural processes specific to the acute and sustained phases of verum and SHAM acupuncture," Journal of Magnetic Resonance Imaging, vol. 33, no. 1, pp. 33-40, 2011.

[79] C.-H. Hsieh, C.-W. Hsieh, J.-H. Wu, Q.-F. Wang, and J.-H. Chen, "Different brain network activations induced by modulation and nonmodulation laser acupuncture," Evidence-Based Complementary and Alternative Medicine, vol. 2011, Article ID 951258, 8 pages, 2011.

[80] T. Witzel, V. Napadow, N. W. Kettner, M. G. Vangel, M. S. Hämäläinen, and R. P. Dhond, "Differences in cortical response to acupressure and electroacupuncture stimuli," $B M C$ Neuroscience, vol. 12, article 73, 2011.

[81] M. J.-L. Chen, T. Thompson, J. Kropotov, and J. H. Gruzelier, "Beneficial effects of electrostimulation contingencies on sustained attention and electrocortical activity," CNS Neuroscience \& Therapeutics, vol. 17, no. 5, pp. 311-326, 2011.

[82] W.-S. Jung, S.-U. Park, J.-M. Park et al., "Changes in SPECT cerebral blood flow following japanese style, superficial acupuncture at LI- 4 and LI-11 in healthy volunteers," The Journal of Alternative and Complementary Medicine, vol. 17, no. 4, pp. 357-362, 2011.

[83] H. Cheng, X.-T. Zhang, H. Yan et al., "Differential temporal neural responses of pain-related regions by acupuncture at acupoint ST36: a magneto-encephalography study," Chinese Medical Journal, vol. 124, no. 8, pp. 1229-1234, 2011.

[84] D.-M. Duan, Y. Tu, S. Jiao, and W. Qin, “The relevance between symptoms and magnetic resonance imaging analysis of the hippocampus of depressed patients given electro-acupuncture combined with fluoxetine intervention-a randomized, controlled trial," Chinese Journal of Integrative Medicine, vol. 17, no. 3, pp. 190-199, 2011.

[85] K.-H. Rheu, G.-H. Jahng, C.-W. Ryu, and S. Lim, "Investigation of the delayed neuronal effects of acupuncture manipulations," The Journal of Alternative and Complementary Medicine, vol. 17, no. 11, pp. 1021-1027, 2011.

[86] Y. Feng, L. Bai, Y. Ren et al., "Investigation of the largescale functional brain networks modulated by acupuncture," Magnetic Resonance Imaging, vol. 29, no. 7, pp. 958-965, 2011.

[87] T. Xue, L. Bai, S. Chen et al., "Neural specificity of acupuncture stimulation from support vector machine classification analysis," Magnetic Resonance Imaging, vol. 29, no. 7, pp. 943-950, 2011.

[88] G. Li, J.-M. Liang, P.-W. Li et al., "Physiology and cell biology of acupuncture observed in calcium signaling activated by acoustic shear wave," Pflügers Archiv-European Journal of Physiology, vol. 462, no. 4, pp. 587-597, 2011.

[89] P. Liu, G. Zhou, X. Yang et al., "Power estimation predicts specific function action of acupuncture: an fMRI study," Magnetic Resonance Imaging, vol. 29, no. 8, pp. 1059-1064, 2011.

[90] P. Liu, G. Zhou, Y. Zhang et al., "The hybrid GLM-ICA investigation on the neural mechanism of acupoint ST36: an fMRI study," Neuroscience Letters, vol. 479, no. 3, pp. 267-271, 2010.

[91] W. Q. Qiu, J. Claunch, J. Kong et al., “The effects of acupuncture on the brain networks for emotion and cognition: an observation of gender differences," Brain Research, vol. 1362, pp. 56-67, 2010.

[92] I. Quah-Smith, P. S. Sachdev, W. Wen, X. Chen, and M. A. Williams, "The brain effects of laser acupuncture in healthy individuals: an FMRI investigation,” PloS ONE, vol. 5, no. 9, Article ID e12619, 2010.

[93] L. Bai, H. Yan, N. Li et al., "Neural specificity of acupuncture stimulation at pericardium 6: evidence from an fMRI study," Journal of Magnetic Resonance Imaging, vol. 31, no. 1, pp. 71-77, 2010.

[94] K. K. S. Hui, V. Napadow, J. Liu et al., "Monitoring acupuncture effects on human brain by fMRI," Journal of Visualized Experiments, no. 38, Article ID e1190, 2010.

[95] Y. Ren, L. Bai, Y. Feng, J. Tian, and K. Li, "Investigation of acupoint specificity by functional connectivity analysis based on graph theory," Neuroscience Letters, vol. 482, no. 2, pp. 95100,2010

[96] C. E. Zyloney, K. Jensen, G. Polich et al., "Imaging the functional connectivity of the Periaqueductal Gray during genuine and sham electroacupuncture treatment," Molecular Pain, vol. 6, article 80, 2010.

[97] Y. Wu, Z. Jin, K. Li et al., "Functional magnetic resonance imaging activation of the brain in children: real acupoint versus sham acupoint," Journal of Child Neurology, vol. 25, no. 7, pp. 849-855, 2010

[98] S.-Y. Cho, G.-H. Jahng, S.-U. Park, W.-S. Jung, S.-K. Moon, and J.-M. Park, "FMRI study of effect on brain activity according to stimulation method at LI11, ST36: painful pressure and 
acupuncture stimulation of same acupoints," Journal of Alternative and Complementary Medicine, vol. 16, no. 4, pp. 489-495, 2010.

[99] L. Li, W. Qin, L. Bai, and J. Tian, "Exploring vision-related acupuncture point specificity with multivoxel pattern analysis," Magnetic Resonance Imaging, vol. 28, no. 3, pp. 380-387, 2010.

[100] J. Sun, W. Qin, M. Dong et al., "Evaluation of group homogeneity during acupuncture stimulation in fMRI studies," Journal of Magnetic Resonance Imaging, vol. 32, no. 2, pp. 298-305, 2010.

[101] W. C. W. Chu, J. C. Y. Wu, D. T. W. Yew et al., "Does acupuncture therapy alter activation of neural pathway for pain perception in irritable bowel syndrome?: A comparative study of true and sham acupuncture using functional magnetic resonance imaging," Journal of Neurogastroenterology and Motility, vol. 18, no. 3, pp. 305-316, 2012.

[102] M.-S. Park, Y.-Y. Sunwoo, K.-S. Jang et al., "Changes in brain FDG metabolism induced by acupuncture in healthy volunteers," Acta Radiologica, vol. 51, no. 8, pp. 947-952, 2010.

[103] A. U. Asghar, G. Green, M. F. Lythgoe, G. Lewith, and H. MacPherson, "Acupuncture needling sensation: the neural correlates of deqi using fMRI," Brain Research, vol. 1315, pp. 111-118, 2010.

[104] L. Bai, J. Tian, C. Zhong et al., "Acupuncture modulates temporal neural responses in wide brain networks: evidence from fMRI study," Molecular Pain, vol. 6, article 73, 2010.

[105] R. E. Harris, J.-K. Zubieta, D. J. Scott, V. Napadow, R. H. Gracely, and D. J. Clauw, "Traditional Chinese acupuncture and placebo (sham) acupuncture are differentiated by their effects on $\mu$ opioid receptors (MORs)," NeuroImage, vol. 47, no. 3, pp. 10771085, 2009.

[106] L. Bai, W. Qin, J. Tian et al., "Time-varied characteristics of acupuncture effects in fMRI studies," Human Brain Mapping, vol. 30, no. 11, pp. 3445-3460, 2009.

[107] V. Napadow, R. Dhond, K. Park et al., "Time-variant fMRI activity in the brainstem and higher structures in response to acupuncture," NeuroImage, vol. 47, no. 1, pp. 289-301, 2009.

[108] M. Sato, M. Inubushi, T. Shiga et al., "Therapeutic effects of acupuncture in patients with rheumatoid arthritis: a prospective study using 18F-FDG-PET,' Annals of Nuclear Medicine, vol. 23, no. 3, pp. 311-316, 2009.

[109] Y. Chae, H. Lee, H. Kim, H. Sohn, J.-H. Park, and H.-J. Park, "The neural substrates of verum acupuncture compared to non-penetrating placebo needle: an fMRI study," Neuroscience Letters, vol. 450, no. 2, pp. 80-84, 2009.

[110] T.-J. Ho, J.-R. Duann, C.-M. Chen et al., "Temporally shifted hemodynamic response model helps to extract acupunctureinduced functional magnetic resonance imaging blood oxygenation-level dependent activities," Chinese Medical Journal, vol. 122, no. 7, pp. 823-829, 2009.

[111] P. Liu, Y. Zhang, G. Zhou et al., "Partial correlation investigation on the default mode network involved in acupuncture: an fMRI study," Neuroscience Letters, vol. 462, no. 3, pp. 183-187, 2009.

[112] Y. Chae, H. Lee, H. Kim et al., "Parsing brain activity associated with acupuncture treatment in Parkinson's diseases," Movement Disorders, vol. 24, no. 12, pp. 1794-1802, 2009.

[113] Y. Zhang, W. Qin, P. Liu et al., "An fMRI study of acupuncture using independent component analysis," Neuroscience Letters, vol. 449, no. 1, pp. 6-9, 2009.

[114] S. Yeo, I.-H. Choe, M. Van Den Noort, P. Bosch, and S. Lim, "Consecutive acupuncture stimulations lead to significantly decreased neural responses," Journal of Alternative and Complementary Medicine, vol. 16, no. 4, pp. 481-487, 2010.
[115] P. Liu, W. Qin, Y. Zhang et al., “Combining spatial and temporal information to explore function-guide action of acupuncture using fMRI," Journal of Magnetic Resonance Imaging, vol. 30, no. 1, pp. 41-46, 2009.

[116] Y.-S. An, S.-K. Moon, I.-K. Min, and D.-Y. Kim, "Changes in regional cerebral blood flow and glucose metabolism following electroacupuncture at LI 4 and LI 11 in normal volunteers," The Journal of Alternative and Complementary Medicine, vol. 15, no. 10, pp. 1075-1081, 2009.

[117] V. Napadow, R. P. Dhond, J. Kim et al., "Brain encoding of acupuncture sensation-coupling on-line rating with fMRI," NeuroImage, vol. 47, no. 3, pp. 1055-1065, 2009.

[118] J. Kong, T. J. Kaptchuk, G. Polich et al., "An fMRI study on the interaction and dissociation between expectation of pain relief and acupuncture treatment," NeuroImage, vol. 47, no. 3, pp. 1066-1076, 2009.

[119] L. Bai, W. Qin, J. Tian et al., "Acupuncture modulates spontaneous activities in the anticorrelated resting brain networks," Brain Research, vol. 1279, pp. 37-49, 2009.

[120] K. K. S. Hui, O. Marina, J. D. Claunch et al., "Acupuncture mobilizes the brain's default mode and its anti-correlated network in healthy subjects," Brain Research, vol. 1287, pp. 84103, 2009.

[121] X. Lai, G. Zhang, Y. Huang et al., "A cerebral functional imaging study by positron emission tomography in healthy volunteers receiving true or sham acupuncture needling," Neuroscience Letters, vol. 452, no. 2, pp. 194-199, 2009.

[122] S.-U. Park, A.-S. Shin, G.-H. Jahng, S.-K. Moon, and J.-M. Park, "Effects of scalp acupuncture versus upper and lower limb acupuncture on signal activation of blood oxygen level dependent (BOLD) fMRI of the brain and somatosensory cortex," Journal of Alternative and Complementary Medicine, vol. 15, no. 11, pp. 1193-1200, 2009.

[123] L. Li, H. Liu, Y.-Z. Li et al., "The human brain response to acupuncture on same-meridian acupoints: evidence from an fMRI study," Journal of Alternative and Complementary Medicine, vol. 14, no. 6, pp. 673-678, 2008.

[124] R. P. Dhond, T. Witzel, M. Hämäläinen, N. Kettner, and V. Napadow, "Spatiotemporal mapping the neural correlates of acupuncture with MEG," The Journal of Alternative and Complementary Medicine, vol. 14, no. 6, pp. 679-688, 2008.

[125] G. Deng, B. L. Hou, A. I. Holodny, and B. R. Cassileth, "Functional magnetic resonance imaging (fMRI) changes and saliva production associated with acupuncture at LI-2 acupuncture point: a randomized controlled study," BMC Complementary and Alternative Medicine, vol. 8, article 37, 2008.

[126] W. Qin, J. Tian, L. Bai et al., "FMRI connectivity analysis of acupuncture effects on an amygdala-associated brain network," Molecular Pain, vol. 4, article 55, 2008.

[127] J. Kong, T. J. Kaptchuk, G. Polich et al., "Expectancy and treatment interactions: a dissociation between acupuncture analgesia and expectancy evoked placebo analgesia," NeuroImage, vol. 45, no. 3, pp. 940-949, 2009.

[128] T.-J. Ho, J.-R. Duann, C.-M. Chen et al., "Carryover effects alter fMRI statistical analysis in an acupuncture study," American Journal of Chinese Medicine, vol. 36, no. 1, pp. 55-70, 2008.

[129] R. P. Dhond, C. Yeh, K. Park, N. Kettner, and V. Napadow, "Acupuncture modulates resting state connectivity in default and sensorimotor brain networks," Pain, vol. 136, no. 3, pp. 407418, 2008.

[130] D. D. Dougherty, J. Kong, M. Webb, A. A. Bonab, A. J. Fischman, and R. L. Gollub, "A combined [11C]diprenorphine PET study 
and fMRI study of acupuncture analgesia," Behavioural Brain Research, vol. 193, no. 1, pp. 63-68, 2008.

[131] V. Napadow, J. Liu, M. Li et al., "Somatosensory cortical plasticity in carpal tunnel syndrome treated by acupuncture," Human Brain Mapping, vol. 28, no. 3, pp. 159-171, 2007.

[132] R. Moncayo, A. Rudisch, M. Diemling, and C. Kremser, "Invivo visualization of the anatomical structures related to the acupuncture points Dai mai and Shenmai by MRI: a single-case pilot study," BMC Medical Imaging, vol. 7, article 4, 2007.

[133] V. Napadow, N. Kettner, J. Liu et al., "Hypothalamus and amygdala response to acupuncture stimuli in carpal tunnel syndrome," Pain, vol. 130, no. 3, pp. 254-266, 2007.

[134] J. D. Schaechter, B. D. Connell, W. B. Stason et al., "Correlated change in upper limb function and motor cortex activation after verum and sham acupuncture in patients with chronic stroke," Journal of Alternative and Complementary Medicine, vol. 13, no. 5, pp. 527-532, 2007.

[135] K. K. S. Hui, E. E. Nixon, M. G. Vangel et al., "Characterization of the 'deqi' response in acupuncture," BMC Complementary and Alternative Medicine, vol. 7, article 33, 2007.

[136] S.-M. Wang, R. T. Constable, F. S. Tokoglu, D. A. Weiss, D. Freyle, and Z. N. Kain, "Acupuncture-induced blood oxygenation level-dependent signals in awake and anesthetized volunteers: a pilot study," Anesthesia and Analgesia, vol. 105, no. 2, pp. 499-506, 2007.

[137] Y. Huang, J. Chen, W. M. Htut, X. Lai, and G. Wik, "Acupuncture increases cerebral glucose metabolism in human vascular dementia," International Journal of Neuroscience, vol. 117, no. 7, pp. 1029-1037, 2007.

[138] S. Liu, W. Zhou, X. Ruan et al., "Activation of the hypothalamus characterizes the response to acupuncture stimulation in heroin addicts," Neuroscience Letters, vol. 421, no. 3, pp. 203-208, 2007.

[139] R. Moncayo, A. Rudisch, C. Kremser, and H. Moncayo, "3DMRI rendering of the anatomical structures related to acupuncture points of the Dai mai, Yin qiao mai and Yang qiao mai meridians within the context of the WOMED concept of lateral tension: implications for musculoskeletal disease," $B M C$ Musculoskeletal Disorders, vol. 8, no. 1, article 33, 2007.

[140] J. Kong, R. L. Gollub, J. M. Webb, J.-T. Kong, M. G. Vangel, and K. Kwong, "Test-retest study of fMRI signal change evoked by electroacupuncture stimulation," NeuroImage, vol. 34, no. 3, pp. 1171-1181, 2007.

[141] V. Napadow, N. Kettner, A. Ryan, K. K. Kwong, J. Audette, and K. K. S. Hui, "Somatosensory cortical plasticity in carpal tunnel syndrome-a cross-sectional fMRI evaluation," NeuroImage, vol. 31, no. 2, pp. 520-530, 2006.

[142] V. C. N. Wong, J.-G. Sun, and D. W. C. Yeung, "Pilot study of efficacy of tongue and body acupuncture in children with visual impairment," Journal of Child Neurology, vol. 21, no. 6, pp. 462473, 2006.

[143] A. C. N. Chen, F.-J. Liu, L. Wang, and L. Arendt-Nielsen, "Mode and site of acupuncture modulation in the human brain: 3D (124-ch) EEG power spectrum mapping and source imaging," NeuroImage, vol. 29, no. 4, pp. 1080-1091, 2006.

[144] K. Li, B. Shan, J. Xu et al., "Changes in FMRI in the human brain related to different durations of manual acupuncture needling," Journal of Alternative and Complementary Medicine, vol. 12, no. 7, pp. 615-623, 2006

[145] V. C. N. Wong, J.-G. Sun, and D. W. C. Yeung, "Pilot study of positron emission tomography (PET) brain glucose metabolism to assess the efficacy of tongue and body acupuncture in cerebral palsy," Journal of Child Neurology, vol. 21, no. 6, pp. 455-462, 2006.

[146] G. Li, C. R. Jack Jr., and E. S. Yang, "An fMRI study of somatosensory-implicated acupuncture points in stable somatosensory stroke patients," Journal of Magnetic Resonance Imaging, vol. 24, no. 5, pp. 1018-1024, 2006.

[147] J. Kong, R. L. Gollub, I. S. Rosman et al., "Brain activity associated with expectancy-enhanced placebo analgesia as measured by functional magnetic resonance imaging," The Journal of Neuroscience, vol. 26, no. 2, pp. 381-388, 2006.

[148] K. K. S. Hui, J. Liu, O. Marina et al., “The integrated response of the human cerebro-cerebellar and limbic systems to acupuncture stimulation at ST 36 as evidenced by fMRI," NeuroImage, vol. 27, no. 3, pp. 479-496, 2005.

[149] Y. Ueda, K. Hayashi, and K. Kuriowa, "The application of fMRI to basic experiments in acupuncture," IEEE Engineering in Medicine and Biology Magazine, vol. 24, no. 2, pp. 47-51, 2005.

[150] C. M. Siedentopf, F. Koppelstaetter, I. A. Haala et al., "Laser acupuncture induced specific cerebral cortical and subcortical activations in humans," Lasers in Medical Science, vol. 20, no. 2, pp. 68-73, 2005.

[151] V. Napadow, N. Makris, J. Liu, N. W. Kettner, K. K. Kwong, and K. K. S. Hui, "Effects of electroacupuncture versus manual acupuncture on the human brain as measured by fMRI," Human Brain Mapping, vol. 24, no. 3, pp. 193-205, 2005.

[152] V. Napadow, R. P. Dhond, P. Purdon et al., "Correlating acupuncture $\mathrm{FMRI}$ in the human brainstem with heart rate variability," in Proceedings of the IEEE 27th Annual Conference on Engineering in Medicine and Biology, pp. 4496-4499, Shanghai, China, September 2005.

[153] S.-S. Jeun, J.-S. Kim, B.-S. Kim et al., "Acupuncture stimulation for motor cortex activities: a 3T fMRI Study," American Journal of Chinese Medicine, vol. 33, no. 4, pp. 573-578, 2005.

[154] B. Yan, K. Li, J. Xu et al., "Acupoint-specific fMRI patterns in human brain," Neuroscience Letters, vol. 383, no. 3, pp. 236-240, 2005.

[155] J. Kong, N. S. White, K. K. Kwong et al., "Using fMRI to dissociate sensory encoding from cognitive evaluation of heat pain intensity," Human Brain Mapping, vol. 27, no. 9, pp. 715721, 2006.

[156] S.-S. Yoo, E.-K. Teh, R. A. Blinder, and F. A. Jolesz, “Modulation of cerebellar activities by acupuncture stimulation: evidence from fMRI study," NeuroImage, vol. 22, no. 2, pp. 932-940, 2004.

[157] J. L. Fang, T. Krings, J. Weidemann, I. G. Meister, and A. Thron, "Functional MRI in healthy subjects during acupuncture: different effects of needle rotation in real and false acupoints," Neuroradiology, vol. 46, no. 5, pp. 359-362, 2004.

[158] W.-C. Liu, S. C. Feldman, D. B. Cook et al., "fMRI study of acupuncture-induced periaqueductal gray activity in humans," NeuroReport, vol. 15, no. 12, pp. 1937-1940, 2004.

[159] W.-T. Zhang, Z. Jin, F. Luo, L. Zhang, Y.-W. Zeng, and J.-S. Han, "Evidence from brain imaging with fMRI supporting functional specificity of acupoints in humans," Neuroscience Letters, vol. 354, no. 1, pp. 50-53, 2004.

[160] G. Litscher, D. Rachbauer, S. Ropele et al., "Acupuncture using laser needles modulates brain function: first evidence from functional transcranial Doppler sonography and functional magnetic resonance imaging," Lasers in Medical Science, vol. 19, no. 1, pp. 6-11, 2004.

[161] G. Li, R. T. F. Cheung, Q.-Y. Ma, and E. S. Yang, "Visual cortical activations on fMRI upon stimulation of the vision-implicated acupoints," NeuroReport, vol. 14, no. 5, pp. 669-673, 2003. 
[162] W.-T. Zhang, Z. Jin, G.-H. Cui et al., "Relations between brain network activation and analgesic effect induced by low vs. high frequency electrical acupoint stimulation in different subjects: a functional magnetic resonance imaging study," Brain Research, vol. 982, no. 2, pp. 168-178, 2003.

[163] L. Yin, X. Jin, W. Qiao et al. et al., "PET imaging of brain function while puncturing the acupoint ST36," Chinese Medical Journal, vol. 116, no. 12, pp. 1836-1839, 2003.

[164] G. Li, H.-L. Liu, R. T. F. Cheung et al., "An fMRI study comparing brain activation between word generation and electrical stimulation of language-implicated acupoints," Human Brain Mapping, vol. 18, no. 3, pp. 233-238, 2003.

[165] Y. H. Guan, C. T. Zuo, J. Zhao, and X. T. Lin, "Regional cerebral metabolic changes after acupuncture by FDG PET: effects and methodology," Nuclear Science and Techniques, vol. 13, no. 4, pp. 224-229, 2002.

[166] M.-T. Wu, J.-M. Sheen, K.-H. Chuang et al., "Neuronal specificity of acupuncture response: a fMRI study with electroacupuncture," NeuroImage, vol. 16, no. 4, pp. 1028-1037, 2002.

[167] I. K. Gareus, M. Lacour, A.-C. Schulte, and J. Hennig, "Is there a BOLD response of the visual cortex on stimulation of the vision-related acupoint GB 37?" Journal of Magnetic Resonance Imaging, vol. 15, no. 3, pp. 227-232, 2002.

[168] C. M. Siedentopf, S. M. Golaszewski, F. M. Mottaghy, C. C. Ruff, S. Felber, and A. Schlager, "Functional magnetic resonance imaging detects activation of the visual association cortex during laser acupuncture of the foot in humans," Neuroscience Letters, vol. 327, no. 1, pp. 53-56, 2002.

[169] M. Bäcker, M. G. Hammes, M. Valet et al., "Different modes of manual acupuncture stimulation differentially modulate cerebral blood flow velocity, arterial blood pressure and heart rate in human subjects," Neuroscience Letters, vol. 333, no. 3, pp. 203-206, 2002.

[170] M.-T. Wu, J.-M. Sheen, S.-L. Chin et al., “"Visual” and "auditroy" cortical activation by acupuncture: is there a specific acupoint-cortical correlation? A fMRI study using controlled electroacupuncture," NeuroImage, vol. 13, no. 6, p. 1282, 2001.

[171] M.-T. Wu, J.-M. Sheen, K.-H. Chuang et al., "'Visual' and "Auditroy" cortical activation by acupuncture has no specific cortical-acupoint correlation-a fMRI study of electroacupuncture with control stimulation," in Proceednigs of the International Society for Magnetic Resonance in Medicine (ISMRM '01), vol. 9, p. 537, 2001.

[172] G. Biella, M. L. Sotgiu, G. Pellegata, E. Paulesu, I. Castiglioni, and F. Fazio, "Acupuncture produces central activations in pain regions," NeuroImage, vol. 14, no. 1, pp. 60-66, 2001.

[173] M. Fukunaga, Y. Someya, C. Tanaka et al., "Brain activation under electro-acupuncture stimulation using functional MRI," NeuroImage, vol. 11, no. 5, supplement, p. s862, 2000.

[174] K. K. S. Hui, J. Liu, N. Makris et al., "Acupuncture modulates the limbic system and subcortical gray structures of the human brain: evidence from fMRI studies in normal subjects," Human Brain Mapping, vol. 9, no. 1, pp. 13-25, 2000.

[175] M.-T. Wu, J.-C. Hsieh, J. Xiong et al., “Central nervous pathway for acupunture stimulation: localization of processing with functional MR imaging of the brain-preliminary experience," Radiology, vol. 212, no. 1, pp. 133-141, 1999.

[176] G. Litscher, G. Schwarz, A. Sandner-Kiesling, and I. Hadolt, "Robotic transcranial Doppler sonography probes and acupuncture," International Journal of Neuroscience, vol. 95, no. 1-2, pp. 1-15, 1998.
[177] J. E. Desmond and G. H. Glover, "Estimating sample size in functional MRI (fMRI) neuroimaging studies: statistical power analyses," Journal of Neuroscience Methods, vol. 118, no. 2, pp. 115-128, 2002.

[178] S. Hayasaka, A. M. Peiffer, C. E. Hugenschmidt, and P. J. Laurienti, "Power and sample size calculation for neuroimaging studies by non-central random field theory," NeuroImage, vol. 37, no. 3, pp. 721-730, 2007.

[179] R. A. Poldrack, "The future of fMRI in cognitive neuroscience," NeuroImage, vol. 62, no. 2, pp. 1216-1220, 2012.

[180] C. S. Xu, C. F. Li, J. Yang et al., "Effects of sample size on cerebral response to acupuncture with fMRI," Chinese Imaging Journal of Integrated Traditional and Western Medicine, vol. 9, no. 4, pp. 289-308, 2011.

[181] S. G. Potkin, G. Alva, K. Fleming et al., "A PET study of the pathophysiology of negative symptoms in schizophrenia," American Journal of Psychiatry, vol. 159, no. 2, pp. 227-237, 2002.

[182] J. V. Pardo, J. T. Lee, S. A. Sheikh et al., "Where the brain grows old: decline in anterior cingulate and medial prefrontal function with normal aging," NeuroImage, vol. 35, no. 3, pp. 1231-1237, 2007.

[183] S. A. Chance, "Subtle changes in the ageing human brain," Nutrition and Health, vol. 18, no. 3, pp. 217-224, 2006.

[184] S. Paradiso, J. G. Vaidya, L. M. McCormick, A. Jones, and R. G. Robinson, "Aging and alexithymia: association with reduced right rostral cingulate volume," The American Journal of Geriatric Psychiatry, vol. 16, no. 9, pp. 760-769, 2008.

[185] S. Basic, S. Hajnsek, Z. Poljakovic, M. Basic, V. Culic, and I. Zadro, "Determination of cortical language dominance using functional transcranial Doppler sonography in left-handers," Clinical Neurophysiology, vol. 115, no. 1, pp. 154-160, 2004.

[186] D. Damore, J. Rutledge, S. Pan, N. Knotek, and M. Ramundo, "Handedness effects on procedural training in pediatrics," Clinical Pediatrics, vol. 48, no. 2, pp. 156-160, 2009.

[187] H. R. Siebner, C. Limmer, A. Peinemann et al., "Long-term consequences of switching handedness: a positron emission tomography study on handwriting in 'converted' left-handers," The Journal of Neuroscience, vol. 22, no. 7, pp. 2816-2825, 2002.

[188] R. de La Fuente-Fernández, A. Kishore, D. B. Calne, T. J. Ruth, and A. J. Stoessl, "Nigrostriatal dopamine system and motor lateralization," Behavioural Brain Research, vol. 112, no. 1-2, pp. 63-68, 2000.

[189] Y. Hu, Q. Xu, K. Li et al., "Gender differences of brain glucose metabolic networks revealed by FDG-PET: evidence from a large cohort of 400 young adults," PLoS ONE, vol. 8, no. 12, Article ID e83821, 2013.

[190] J. Kong, P.-C. Tu, C. Zyloney, and T.-P. Su, "Intrinsic functional connectivity of the periaqueductal gray, a resting fMRI study," Behavioural Brain Research, vol. 211, no. 2, pp. 215-219, 2010.

[191] B. Lv, J. Li, H. He et al., "Gender consistency and difference in healthy adults revealed by cortical thickness," NeuroImage, vol. 53, no. 2, pp. 373-382, 2010.

[192] J. P. Rushton and C. D. Ankney, "Brain size and cognitive ability: correlations with age, sex, social class, and race," Psychonomic Bulletin \& Review, vol. 3, no. 1, pp. 21-36, 1996.

[193] W. C. Drevets, J. L. Price, J. R. Simpson Jr. et al., "Subgenual prefrontal cortex abnormalities in mood disorders," Nature, vol. 386, no. 6627, pp. 824-827, 1997.

[194] D. S. Veldhuijzen, M. L. Keaser, D. S. Traub, J. Zhuo, R. P. Gullapalli, and J. D. Greenspan, "The role of circulating sex hormones in menstrual cycle-dependent modulation of painrelated brain activation," Pain, vol. 154, no. 4, pp. 548-559, 2013. 
[195] G. Hagemann, T. Ugur, E. Schleussner et al., "Changes in brain size during the menstrual cycle," PLoS ONE, vol. 6, no. 2, Article ID e14655, 2011.

[196] C.-H. Tu, D. M. Niddam, T.-C. Yeh et al., "Menstrual pain is associated with rapid structural alterations in the brain," Pain, vol. 154, no. 9, pp. 1718-1724, 2013.

[197] C.-H. Tu, D. M. Niddam, H.-T. Chao et al., "Brain morphological changes associated with cyclic menstrual pain," Pain, vol. 150, no. 3, pp. 462-468, 2010.

[198] S. Naruse, K. Mori, M. Kurihara et al., "Chorioretinal blood flow changes following acupuncture between thumb and forefinger," Nippon GankaGakkaiZasshi, vol. 104, no. 10, pp. 717-723, 2000.

[199] H. MacPherson, A. White, M. Cummings, K. A. Jobst, K. Rose, and R. C. Niemtzow, "Standards for reporting interventions in controlled trials of acupuncture: the STRICTA recommendations," Journal of Alternative \& Complementary Medicine, vol. 8, no. 1, pp. 85-89, 2002.

[200] J. Kong, R. Gollub, T. Huang et al., "Acupuncture De Qi, from qualitative history to quantitative measurement," The Journal of Alternative and Complementary Medicine, vol. 13, no. 10, pp. 1059-1070, 2007.

[201] S.-B. Xu, B. Huang, C.-Y. Zhang et al., "Effectiveness of strengthened stimulation during acupuncture for the treatment of Bell palsy: a randomized controlled trial," Canadian Medical Association Journal, vol. 185, no. 6, pp. 473-479, 2013. 


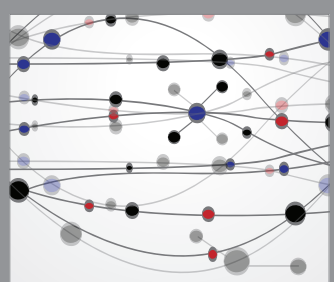

The Scientific World Journal
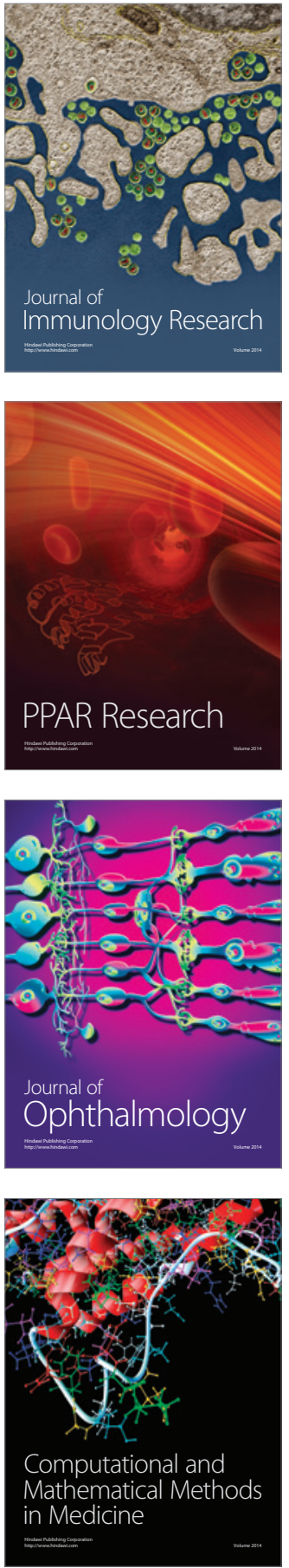

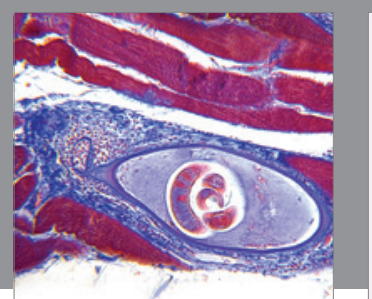

Gastroenterology Research and Practice

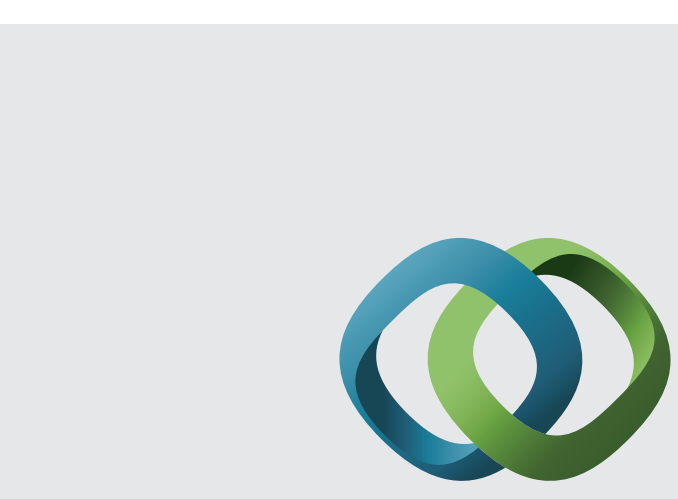

\section{Hindawi}

Submit your manuscripts at

http://www.hindawi.com
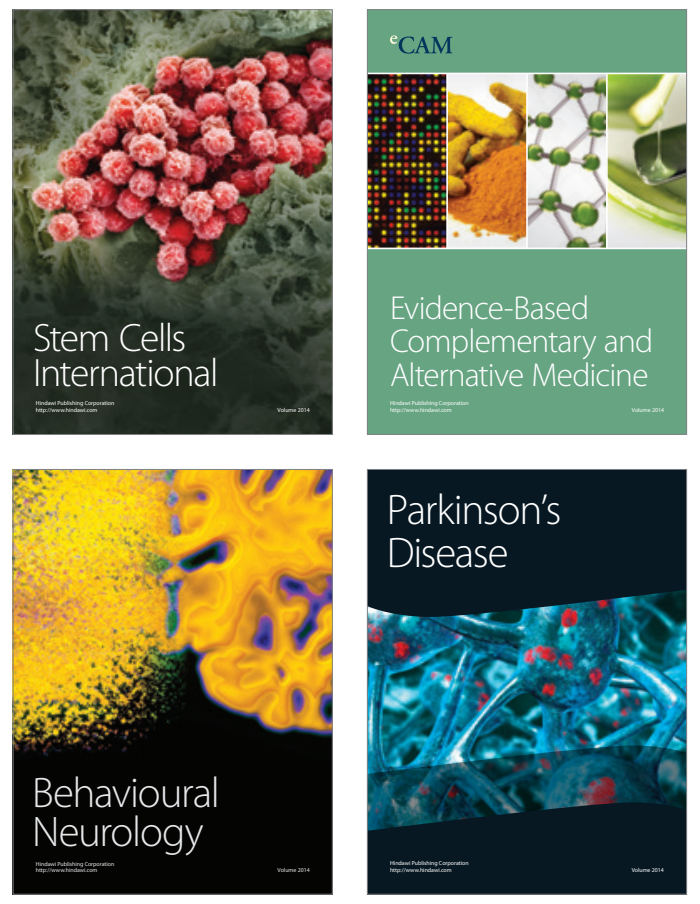
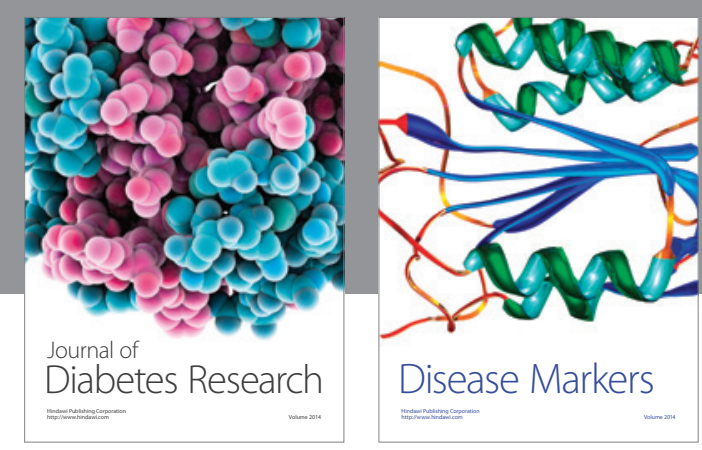

Disease Markers
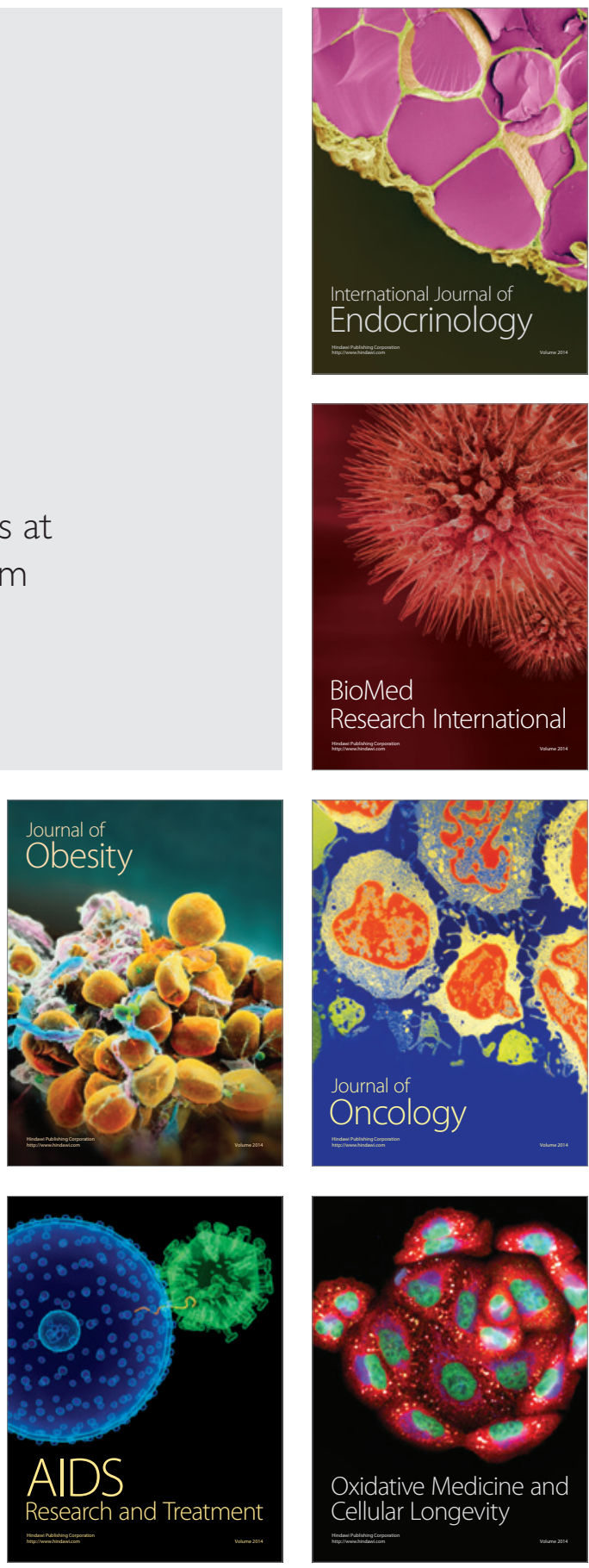